\title{
(6) OPEN ACCESS \\ Australian adult smokers' responses to plain packaging with larger graphic health warnings 1 year after implementation: results from a national cross-sectional tracking survey
}

\author{
Melanie Wakefield, Kerri Coomber, Meghan Zacher, Sarah Durkin, Emily Brennan, \\ Michelle Scollo
}

- Additional material is published online only. To view please visit the journal online (http://dx.doi.org/10.1136/ tobaccocontrol-2014-052050).

Centre for Behavioural Research in Cancer, Cancer Council Victoria, Melbourne, Victoria, Australia

Correspondence to Professor Melanie Wakefield, Centre for Behavioural Research in Cancer, Cancer Council Victoria, 615 St Kilda Rd, Melbourne, VIC 3004, Australia; melanie.wakefield@ cancervic.org.au

Received 25 September 2014 Revised 15 December 2014 Accepted 16 December 2014

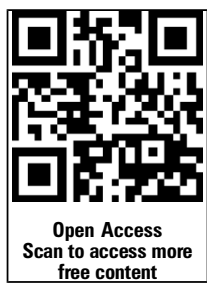

CrossMark

To cite: Wakefield $M$, Coomber $\mathrm{K}$, Zacher $\mathrm{M}$, et al. Tob Control 2015;24 ii17-ii25.

\section{ABSTRACT}

Background We assessed whether the Australian plain packs with larger graphic health warnings (GHWs) achieved three specific objectives of reducing the appeal of tobacco, increasing health warning effectiveness and reducing the ability of packaging to mislead about smoking harms.

Methods We compared responses from continuous cross-sectional telephone surveys of $n=2176$ cigarette smokers during pre-plain packaging (April-September 2012, pre-PP) with $n=759$ surveyed in the transition period (October-November 2012) and $n=4240$ during the first year of implementation (December 2012November 2013, PP year 1), using multivariate logistic regression analyses.

Results From pre-PP to PP year 1, more smokers disliked their pack $(p<0.001)$, perceived lower pack appeal $(p<0.001)$, lower cigarette quality $(p<0.001)$, lower satisfaction $(p<0.001)$ and lower value $(p<0.001)$ and disagreed brands differed in prestige $(p=0.003)$. There was no change in perceived differences in taste of different brands. More smokers noticed GHWs $(p<0.001)$, attributed much motivation to quit to GHWs $(p<0.001)$, avoided specific GHWs when purchasing $(p<0.001)$, and covered packs $(p<0.001)$, with no change in perceived exaggeration of harms. PP year 1 saw an increased proportion believing that brands do not differ in harmfulness $(p=0.004)$, but no change in the belief that variants do not differ in strength or the perceived harmfulness of cigarettes compared with a year ago. Interactions signified greater change for four outcomes assessing aspects of appeal among young adults and two appeal outcomes among mid-aged adults.

Conclusions The specific objectives of plain packaging were achieved and generally sustained among adult smokers up to 12 months after implementation.

\section{INTRODUCTION}

In late 2012, Australia became the first nation to implement plain packaging of tobacco products. ${ }^{1}$ As described further in Scollo et $a l^{2}$ (this supplement), Australian tobacco manufacturers were required to produce only plain packs from 1 October 2012 and retailers were prohibited from selling anything but these from 1 December 2012. Packs were required to be a standard drab dark brown, with brand and variant names appearing in a standard font and position. At the same time, a complementary Information Standard ${ }^{3}$ mandated a set of 14 new graphic health warnings (GHWs)enlarged from $30 \%$ to $75 \%$ of the front of tobacco packs while maintaining $90 \%$ of the back-seven of which appeared on new plain packs as they rolled out onto the market. The selection of the colour for Australian plain packs and the exact content, size and placement of the refreshed and enlarged GHWs were determined after a series of experimental and qualitative studies to test which pack colour consumers found least appealing, and the nature and format of GHWs on plain packs that were most salient, relevant and believable. ${ }^{4-7}$ Most smokers reported using plain packs with enlarged GHWs during November 2012. ${ }^{8}$ Plain packs with the second set of seven larger GHWs rolled out from August 2013 and were used by most during October 2013. ${ }^{2}$

The specific aims of the Tobacco Plain Packaging Act 2011 ${ }^{1}$ were to: (A) reduce the appeal of tobacco products to consumers; (B) increase the effectiveness of health warnings on retail packaging of tobacco products and $(\mathrm{C})$ reduce the ability of retail packaging of tobacco products to mislead consumers about the harmful effects of smoking. Through the achievement of these aims in the longer term, as part of a comprehensive suite of tobacco control methods, it was intended that the legislation would contribute to efforts to reduce smoking rates by discouraging people from taking up smoking, encouraging smokers to quit and discouraging relapse. ${ }^{1}$

The evidence base for the plain packaging legislation was supported not just by many qualitative and experimental research studies comparing plain packs with increasingly or fully branded packs, ${ }^{9-11}$ but by several decades of research that had conclusively established the causal role of tobacco marketing in the initiation of tobacco use and the beneficial impact of tobacco marketing restrictions on reducing tobacco uptake and use. ${ }^{12-14}$ The legislation represented the next logical progression for tighter marketing restrictions in a nation where packaging had become one of the few remaining avenues for continued tobacco promotion ${ }^{15}$ (this supplement).

A large number of qualitative and experimental studies summarised in recent reviews, ${ }^{9-11}$ including several naturalistic studies where smokers were assigned to carry and smoke from fully branded or plain packs over several weeks, ${ }^{16-18}$ have demonstrated plain packaging can reduce elements of the 
appeal of tobacco products, as judged by measures of reduced attractiveness, liking, prestige, stylishness, quality, satisfaction and taste, ${ }^{16-28}$ and that smokers of plain packs are associated with less desirable personality attributes. ${ }^{19} \quad \begin{array}{llllll}20 & 24 & 25 & 28 & 29\end{array}$ Reductions in measures of appeal have been repeatedly evident in studies of youth and young adults, ${ }^{10}{ }^{11}$ consistent with the critical role played by brand image during youth and young adulthood, the period when smoking behaviour develops and brand preferences are established. ${ }^{12}{ }^{13}$ Experimental and naturalistic studies also suggest plain packaging makes health warnings more salient, with warnings being better recalled and

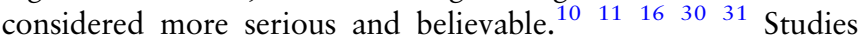
also suggest that plain packaging can redress smokers' misconceptions about product harm, although findings have been more variable, depending on the plain pack colour used and presence of descriptive variant names. ${ }^{10} 11$ A common feature of the qualitative and experimental studies of plain packaging conducted to date is that most have involved only a short period of exposure, so responses may be attributable to pack novelty. Population-based study of consumer responses where plain packaging has become the norm such as in Australia is important for understanding 'real world' effects.

While other papers in this volume have examined early responses of youth to the new packaging, ${ }^{32} 33$ the current study aimed to evaluate the effectiveness of plain packaging with larger GHWs among Australian adult cigarette smokers in achieving the three specific aims of reducing the appeal of tobacco, increasing GHW effectiveness and correcting misperceptions of harm. Since plain packaging was implemented at the same time as larger and refreshed GHWs, this study necessarily examines outcomes of these two packaging changes in aggregate.

It is expected that elements of packaging appeal should reduce after the introduction of the packaging changes, since brand colours and designs on packs were replaced with the same unattractive colour and the GHWs took up a greater proportion of the pack. We also expected perceived differences between brands and variants to be undermined once all packs are plain and their distinctive brand-associated colour and design connotations are replaced with a standard drab brown. Further, the larger refreshed GHWs would be expected to be noticed more because of their increased size and imagery and presentation against a drab background. If credible, these GHWs should then provide more motivation to quit. ${ }^{34}$ Achievement of change in these kinds of proximal outcomes in the first instance would provide confidence that the packaging changes are working as intended, ${ }^{34}$ subsequent to other investigations of more distal outcomes pertaining to reduced smoking uptake or progress towards quitting ${ }^{35}$ (this supplement).

\section{METHODS}

\section{Study design and participants}

The National Plain Packaging Tracking Survey employed a continuous cross-sectional design, with an average of 100 interviews completed per week from April 2012-March 2014. Data collection was suspended for 2 weeks over each December-January holiday period. Telephone interviews with adult smokers (respondents who smoked daily or weekly, or who smoked monthly or less-than monthly and self-identified as smokers) and recent quitters (quit in the last year) were conducted in English. Respondents were recruited using a dual-frame sample design, with half of all respondents approached via landline random digit dialling (RDD) and half by mobile phone RDD. For the landline sample, to correct for over-representation of older female at-home respondents, ${ }^{37}$ interviewers asked to speak to the youngest male aged 18-69 years, and if not available, the youngest female. The mean monthly response rate, adjusted for those who declined to be formally screened but may have been in-scope for the survey, was $57 \%$ and this did not vary over the survey period. Further detail on survey methods is available in a Technical Report (see Supplementary Technical report). ${ }^{38}$

The current study used responses from smokers of factorymade or roll-your-own cigarettes interviewed between April 2012 and November 2013 inclusive, corresponding to 6 months pre-plain packaging (pre-PP, April-September 2012), 2 months of transition (October/November 2012) and 1 year after full implementation (December 2012-November 2013). After excluding $n=149$ respondents who did not provide valid data on all demographic covariates, we analysed responses from 7175 cigarette smokers (weighted $n$; unweighted $n=7133$ ).

\section{Outcome measures}

Questionnaire measures were adapted from other population surveys such as the Australian arm of the International Tobacco Control survey (http://www.itcproject.org/surveys) and tapped similar constructs to those used in past studies to assess appeal, health warning effectiveness and perceived harm. Full details of the questions asked, response options and the way in which responses were aggregated for analysis are provided in the Technical Report (see Supplementary Technical report). ${ }^{38}$

\section{Appeal-related outcomes}

As a general measure of overall appeal, the extent to which respondents liked the look of their current pack was rated on a 5 -point scale from 'strongly agree' to 'strongly disagree' (dichotomised into disagree/strongly disagree vs neither/agree/strongly agree). Smokers were also asked to rate their current cigarettes or tobacco as 'higher', 'lower' or 'about the same' compared with a year ago, in terms of quality, ${ }^{16} 1922 \quad 26$ satisfaction, ${ }^{19}$ value for money ${ }^{19}$ and appeal of the packaging (coded as lower than a year ago vs higher/about the same). ${ }^{19-23}$ Additionally, smokers were asked whether or not there were differences between brands in prestige (no vs yes/do not know) $)^{192025}$ and on a 4-point scale from 'not at all different' to 'very different', how different cigarette brands were in taste (not at all different vs a little/somewhat/very different/do not know). ${ }^{21} 2527$

\section{Health warning effectiveness outcomes}

Noticeability of GHWs was assessed by asking "When you look at a cigarette/tobacco pack, what do you usually notice first: the warning labels, or other aspects of the pack, such as branding?" (noticed the warnings first vs other responses). ${ }^{34} 39$ Respondents were also asked whether they agreed/disagreed that the dangers of smoking had been exaggerated (somewhat/strongly disagree vs neutral/agree responses) as an indicator of perceived credibility of the GHWs. ${ }^{34} 39$ Cognitive response to warnings was measured by asking smokers to what extent the health warnings on packs made them more motivated to quit (much more vs not at all/a little/somewhat). ${ }^{39-41}$ Avoidant responses were measured with two questions: whether in the past month they had asked for a pack with a different health warning on it (yes vs no) ) $^{39} 42$ and how often in the past month they had covered up or concealed their pack or put their cigarettes in another container (several or many times vs other responses). ${ }^{16223940}$

\section{Perceived harm outcomes}

Smokers were asked whether or not there were differences between brands in harm (no vs yes/do not know) 202127 and as 
for the appeal-related outcomes, to rate their current cigarettes or tobacco as 'higher', 'lower' or 'about the same' compared with a year ago, in terms of harmfulness (higher vs other responses). Although descriptive brand variant names persisted on plain packs, the pack colours that had previously signified different tar or strength levels were standardised to dark drab brown, so it was of interest to examine whether consumers continued to perceive differences in strength between brand variants. Smokers were therefore asked to rate on a 4-point scale from 'not at all different' to 'very different', how different brand variants are in strength (not at all different vs other responses). ${ }^{19} 2643$

\section{Covariates}

Data were collected on sex, age and highest educational attainment. The Heaviness of Smoking Index (HSI) assessed nicotine dependence using a 0 (low) to 6 (high) score based on the sum of daily cigarette consumption and minutes to first cigarette of the day, ${ }^{44}$ with HSI for non-daily smokers coded as zero. We used the Socio-Economic Indices for Areas index of relative disadvantage $^{45}$ to measure socioeconomic status (SES), which was based on each respondent's residential postcode (low $=$ quintiles $1-2$; mid =quintiles 3-4; high =quintile 5).

Smokers' responses might have been influenced by tobacco-related media activity and tobacco prices. Potential exposure to televised antismoking advertising campaigns was estimated using monthly Target Audience Rating Points (TARPs). TARPs are a product of the percentage of the audience exposed

Table 1 Characteristics of current smokers, by study period

\begin{tabular}{|c|c|c|c|}
\hline & $\begin{array}{l}\text { Pre-PP } \\
9 \text { April-30 } \\
\text { September } \\
2012\end{array}$ & $\begin{array}{l}\text { Transition } \\
1 \text { October-30 } \\
\text { November } \\
2012\end{array}$ & $\begin{array}{l}\text { PP year } 1 \\
1 \text { December } \\
2012-30 \\
\text { November } 2013\end{array}$ \\
\hline Total & $\begin{array}{l}\mathrm{N}=2176 \\
\mathrm{n}(\%)\end{array}$ & $\begin{array}{l}N=759 \\
n(\%)\end{array}$ & $\begin{array}{l}\mathrm{N}=4240 \\
\mathrm{n}(\%)\end{array}$ \\
\hline \multicolumn{4}{|l|}{ Sex } \\
\hline Male & $1191(55)$ & $416(55)$ & $2326(55)$ \\
\hline Female & $985(45)$ & $342(45)$ & $1914(45)$ \\
\hline \multicolumn{4}{|l|}{ Age } \\
\hline $18-29$ & $641(29)$ & $213(28)$ & $1171(28)$ \\
\hline $30-49$ & 963 (44) & $352(46)$ & $1973(47)$ \\
\hline $50-69$ & $572(26)$ & $193(25)$ & $1096(26)$ \\
\hline \multicolumn{4}{|l|}{ Education } \\
\hline $\begin{array}{l}\text { Less than high } \\
\text { school }\end{array}$ & $648(30)$ & $281(37)$ & $1381(33)$ \\
\hline $\begin{array}{l}\text { Completed high } \\
\text { school/some } \\
\text { tertiary }\end{array}$ & $1248(57)$ & $382(50)$ & $2318(55)$ \\
\hline Tertiary or above & $280(13)$ & $96(13)$ & $541(13)$ \\
\hline \multicolumn{4}{|l|}{ Socioeconomic status } \\
\hline Low & $825(38)$ & 297 (39) & $1724(41)$ \\
\hline Mid & $912(42)$ & $329(43)$ & $1778(42)$ \\
\hline \multirow[t]{2}{*}{ High } & $439(20)$ & $132(17)$ & $738(17)$ \\
\hline & Mean (SE) & Mean (SE) & Mean (SE) \\
\hline $\begin{array}{l}\text { Heaviness of } \\
\text { Smoking Index (0-6) }\end{array}$ & $2.07(0.04)$ & $2.12(0.07)$ & $2.17(0.03)$ \\
\hline $\begin{array}{l}\text { Antismoking } \\
\text { advertising in past } \\
3 \text { months (TARPs) }\end{array}$ & $1816(20.7)$ & $1237(29.4)$ & $1467(13.9)$ \\
\hline
\end{tabular}

Wakefield M, et al. Tob Control 2015;24:ii17-ii25. doi:10.1136/tobaccocontrol-2014-052050 to an advertisement (reach) and the average number of times the target audience is exposed (frequency). Thus, 100 TARPs would represent $100 \%$ of the target audience receiving one advertisement per month, or 50\% reached twice. TARPs for each media market were sourced from AC Nielsen/OZTAM Australian television audience measurements for adults aged $18+$ years. We used advertising exposure over the 3 months prior to interview, based on research demonstrating advertising effects within this time frame $^{46} 47$ (mean 3-month TARPs=1548; SE=11.04). Cigarette costliness in the month of interview was calculated as the ratio of the average recommended retail price of the top 10 brands (obtained from Australian Retail Tobacconist, February-April 2012 to January-March 2014 and weighted by market share) to the average weekly earnings for each respondents' jurisdiction of residence. ${ }^{48}$ Similar to the method of Dunlop et al, ${ }^{38}$ we used percentage change in costliness over the past 3 months as the covariate (mean percentage costliness change for total survey period $=0.173, \mathrm{SE}=0.010$; months of excise/customs duty indexation; August 2012 $=-0.095, \mathrm{SE}=0.034$; February $2013=3.37$, $\mathrm{SE}=0.044$; August $2013=0.327, \mathrm{SE}=0.65$ ).

\section{Statistical analyses}

Data were weighted to account for telephony status (landline or mobile phone), gender, age by education and state of residence (see Supplementary Technical report). ${ }^{38}$ All statistical analyses were conducted using Stata V.12.1 ${ }^{50}$ using weighted data (using the svy command with ' $\mathrm{p}$ ' weights). In addition, an unconditional approach (ie, the 'subpopulation' command in Stata V.12.1) was used to limit the sample as appropriate for each set of analyses, ensuring correct estimation of the SEs. To test whether outcomes differed between three phases of plain packaging implementation (pre-PP (referent), transition and during plain packaging (PP year 1)), we used a series of unadjusted and adjusted logistic regression analysis. All adjusted models included HSI, demographic characteristics, recent antismoking campaign activity and change in cigarette costliness as covariates. We tested for interactions between phase (pre-PP vs PP year 1 ) and age (18-29; 30-49; 50-69 years), sex and SES (low, mid and high) for all outcomes. In tables we present unadjusted and adjusted models, and adjusted models for interactions. For brevity, we refer only to adjusted percentages and models in text. For the PP year 1 phase, we also examined the form of change over time by examining adjusted regression models that included linear and quadratic terms for month. If the quadratic term was not significant, we present results from a model with the linear term for month only. The presence of a significant linear term within PP year 1 indicates a significant linear increase (or decrease) within the year, while the additional presence of a significant quadratic term signifies the increase (or decrease) was curvilinear over the months, that is, that it reached a peak (or trough) and then declined (increased) again.

Finally, sensitivity testing examined whether the inclusion of December/January season variables influenced the pattern of observed findings in adjusted models. On the basis of studies examining quitting interest and behaviours, ${ }^{51}$ we constructed indicator measures of season for the last two survey weeks in December prior to Christmas (less interest and quitting) and the first 2 weeks of January (more interest and quitting).

\section{RESULTS}

Table 1 shows the characteristics of the cigarette smokers who were interviewed-2176 pre-PP, 759 during transition and 4240 during PP year 1, including distribution of covariates. 


\section{Appeal-related outcomes}

Compared with the pre-PP period (58.6\%), a significantly greater adjusted proportion of smokers in the PP year 1 period reported they disliked their pack $(85.0 \%)$, with this higher proportion being maintained throughout PP year 1 (table 2). Compared with pre-PP when $12.3 \%$ of smokers rated their current pack as less appealing than a year ago, significantly more smokers indicated this was the case in PP year 1 (56.2\%). Both of these outcomes changed rapidly, with significant increases also evident in the transition period. From the beginning of PP year 1, odds of reporting lower appeal compared with a year ago declined linearly over each month, although always remaining higher than pre-PP. Odds of reporting that one's cigarettes were of lower quality, lower satisfaction and lower value for money than a year ago were also significantly greater in PP year 1 than in pre-PP (table 2) and these increased proportions remained stable over time.

Compared with pre-PP, in PP year 1 a significantly higher and stable proportion of smokers believed that brands do not differ in prestige. Overall, there was no change in the proportions who believed brands do not differ in taste.
There were significant interactions between age and phase (pre-PP vs PP year 1$)$ for the pack disliking $\left(\mathrm{F}=3.92_{(2,6016)}\right.$, $\mathrm{p}=0.020)$, quality $\left.\left(\mathrm{F}=6.83_{(2,}, 6217\right), \mathrm{p}=0.001\right)$, satisfaction $\left.\left(\mathrm{F}=4.52_{(2)} \quad 6217\right), \quad \mathrm{p}=0.011\right), \quad$ prestige $\left(\mathrm{F}=3.37_{(2,}, 6178\right)$, $\mathrm{p}=0.034)$ and taste $\left(\mathrm{F}=7.60_{(2,6129)}, \mathrm{p}<0.001\right)$ outcomes. While all age groups showed change in the expected direction for pack disliking, quality and satisfaction, younger smokers experienced relatively more change than older smokers (figure 1A-C). Mid-aged (30-49 years) smokers showed significant change in the expected direction for the prestige outcome while younger and older smokers remained stable (figure 1D). For the taste outcome, the younger and mid-aged groups evidenced significant increases in the proportion who believed brands did not differ in taste, while the older age group showed a significant decrease (figure 1E). There were no interactions by sex and phase, or SES and phase for any appeal-related outcomes.

\section{Health warning effectiveness outcomes}

Table 3 shows that GHWs became more noticeable during the transition and PP year 1 periods and this higher

Table 2 Unadjusted and adjusted percentages, ORs and 95\% Cls from logistic regression models predicting appeal-related outcomes*

\begin{tabular}{|c|c|c|c|c|c|c|c|c|c|}
\hline \multirow[b]{2}{*}{ Variable } & \multicolumn{3}{|c|}{ Comparing phases—unadjusted models } & \multicolumn{3}{|c|}{ Comparing phases_-adjusted modelst } & \multicolumn{3}{|c|}{$\begin{array}{l}\text { PP year } 1 \text { trend-adjusted } \\
\text { models }\end{array}$} \\
\hline & Per cent & OR $(95 \% \mathrm{Cl})$ & p Value & Per cent & OR $(95 \% \mathrm{Cl})$ & p Value & Form & OR & p Value \\
\hline \multicolumn{10}{|c|}{ Dislikes pack‡ $(\mathrm{n}=6728)$} \\
\hline Pre-PP & 59.1 & 1.00 & & 58.6 & 1.00 & & & & \\
\hline Transition & 65.0 & $1.28(1.05$ to 1.56$)$ & 0.013 & 65.1 & $1.32(1.08$ to 1.62$)$ & 0.007 & & & \\
\hline PP year 1 & 84.9 & 3.90 (3.39 to 4.46$)$ & $<0.001$ & 85.0 & 4.06 (3.52 to 4.69$)$ & $<0.001$ & Linear & 1.02 & 0.158 \\
\hline \multicolumn{10}{|c|}{ Lower pack appeal than a year ago $¥(n=6179)$} \\
\hline Pre-PP & 12.7 & 1.00 & & 12.3 & 1.00 & & & & \\
\hline Transition & 26.0 & $2.40(1.86$ to 3.10$)$ & $<0.001$ & 26.5 & 2.59 (1.99 to 3.37$)$ & $<0.001$ & & & \\
\hline PP year 1 & 55.8 & 8.63 (7.27 to 10.24$)$ & $<0.001$ & 56.2 & 9.29 (7.79 to 11.09$)$ & $<0.001$ & Linear & 0.97 & 0.004 \\
\hline \multicolumn{10}{|c|}{ Lower quality than a year ago§ $(n=6954)$} \\
\hline Pre-PP & 13.9 & 1.00 & & 14.0 & 1.00 & & & & \\
\hline Transition & 17.2 & $1.29(1.01$ to 1.66$)$ & 0.045 & 17.2 & $1.28(0.99$ to 1.65$)$ & 0.063 & & & \\
\hline PP year 1 & 26.7 & 2.26 (1.93 to 2.64$)$ & $<0.001$ & 26.6 & 2.24 (1.91 to 2.64$)$ & $<0.001$ & Linear & 0.99 & 0.554 \\
\hline \multicolumn{10}{|c|}{ Lower satisfaction than a year ago§ $(n=6954)$} \\
\hline Pre-PP & 12.2 & 1.00 & & 12.3 & 1.00 & & & & \\
\hline Transition & 13.8 & 1.15 (0.87 to 1.51$)$ & 0.319 & 13.9 & 1.15 (0.87 to 1.51$)$ & 0.334 & & & \\
\hline PP year 1 & 20.7 & 1.88 (1.59 to 2.22$)$ & $<0.001$ & 20.6 & 1.85 (1.56 to 2.19$)$ & $<0.001$ & Linear & 0.99 & 0.690 \\
\hline \multicolumn{10}{|c|}{ Lower value than a year ago§ $(n=6901)$} \\
\hline Pre-PP & 50.9 & 1.00 & & 50.4 & 1.00 & & & & \\
\hline Transition & 50.7 & $1.02(0.84$ to 1.22$)$ & 0.870 & 51.6 & 1.05 (0.87 to 1.27$)$ & 0.622 & & & \\
\hline PP year 1 & 56.7 & 1.27 (1.13 to 1.43$)$ & $<0.001$ & 56.8 & 1.30 (1.15 to 1.46$)$ & $<0.001$ & Linear & 1.02 & 0.058 \\
\hline \multicolumn{10}{|c|}{ Believes brands do not differ in prestige $\ddagger(n=6904)$} \\
\hline Pre-PP & 44.7 & 1.00 & & 45.1 & 1.00 & & & & \\
\hline Transition & 42.1 & $0.90(0.75$ to 1.09$)$ & 0.273 & 43.1 & 0.91 (0.75 to 1.11$)$ & 0.373 & & & \\
\hline PP year 1 & 49.9 & $1.23(1.10$ to 1.38$)$ & $<.001$ & 49.5 & 1.21 (1.07 to 1.37$)$ & 0.003 & Linear & 1.01 & 0.310 \\
\hline \multicolumn{10}{|c|}{ Believes brands do not differ in taste $\neq(n=6840)$} \\
\hline Pre-PP & 6.7 & 1.00 & & 6.7 & 1.00 & & & & \\
\hline Transition & 8.1 & $1.23(0.87$ to 1.72$)$ & 0.240 & 8.4 & $1.27(0.90$ to 1.80$)$ & 0.174 & & & \\
\hline PP year 1 & 7.7 & $1.16(0.93$ to 1.45$)$ & 0.190 & 7.7 & 1.17 (0.93 to 1.47$)$ & 0.189 & Linear & 1.02 & 0.250 \\
\hline \multicolumn{10}{|c|}{$\begin{array}{l}\text { Bold text indicates significant findings at } \mathrm{p}<0.05 \text {. } \\
\text { *Valid n's for each model vary because of differences in the number of respondents who were eligible for each question (see below) and the number of missing cases on each outcome. } \\
\text { The pack appeal model excluded } 15.2 \% \text { of cases that were missing, while for all other models missing cases ranged from } 5.1 \% \text { to } 7.6 \% \text {. } \\
\text { tMultivariate models adjusted for age, gender, educational attainment, SES, Heaviness of Smoking Index, past 3-month Target Audience Rating Points for antismoking mass media } \\
\text { campaigns and change in cigarette costliness. } \\
\text { fltems were only asked of cigarette smokers who, when asked to name which brand of FM cigarettes/RYO tobacco they were currently smoking, provided a valid brand name. } \\
\text { Sltems were asked of all cigarette smokers. } \\
\text { FM, factory-made; PP, plain packaging; RYO, roll-your-own; SES, socioeconomic status. }\end{array}$} \\
\hline
\end{tabular}


Figure 1 (A-E) Significant interactions by age group for appeal-related outcomes in adjusted models.

(A) Dislikes pack: 18-29 years: pre-plain packaging (pre-PP) $53.3 \%$, PP year $184.9 \%(\mathrm{OR}=5.07(95 \% \mathrm{Cl}$ 3.78 to 6.81$)), p<0.001$. $30-49$ years: pre-PP $61.2 \%$, PP year $184.4 \%$ (OR=3.47 (2.77 to 4.33)), $\mathrm{p}<0.001$. 50-69 years: pre-PP $60.7 \%$, PP year 1 $86.2 \%(\mathrm{OR}=4.14$ (3.26 to 5.26$))$, $\mathrm{p}<0.001$.

(B) Lower quality: 18-29 years: pre-PP $10.2 \%$, PP year $129.3 \%$ (OR=3.76

(2.63 to 5.38$)), p<0.001 .30-49$ years: pre-PP $14.5 \%$, PP year $124.7 \%$ (OR=1.94 (1.50 to 2.50)), $p<0.001$. 50-69 years: pre-PP $17.3 \%$, PP year 1 $27.2 \%(\mathrm{OR}=1.79$ (1.40 to 2.30$))$, $\mathrm{p}<0.001$.

(C) Lower satisfaction: 18-29 years: pre-PP $10.4 \%$, PP year $121.1 \%$ (OR=2.32 (1.61 to 3.33)), $\mathrm{p}<0.001$. $30-49$ years: pre-PP $12.2 \%$, PP year 1 $21.1 \%(\mathrm{OR}=1.94$ (1.49 to 2.54$))$, $\mathrm{p}<0.001$. 50-69 years: pre-PP $14.7 \%$, $\mathrm{PP}$ year $119.1 \%(\mathrm{OR}=1.37$ (1.05 to 1.78)), $p=0.020$.

(D) Brands do not differ in prestige: 18-29 years: pre-PP $26.9 \%$, PP year 1 $30.3 \%(O R=1.18(0.90$ to 1.55$))$, $p=0.237 .30-49$ years: pre-PP $45.5 \%$, PP year $153.5 \%(\mathrm{OR}=1.38$ (1.14 to $1.66)), p<0.001 .50-69$ years: pre-PP $63.6 \%$, PP year $163.3 \%$ (OR=0.99

(0.80 to 1.21$)), p=0.899$.

(E) Brands do not differ in taste:

18-29 years: pre-PP 3.3\%, PP year 1 $6.8 \%(\mathrm{OR}=2.14$ (1.20 to 3.81$))$, $\mathrm{p}=0.010 .30-49$ years: pre-PP $5.5 \%$, $\mathrm{PP}$ year $18.1 \%(\mathrm{OR}=1.53$ (1.04 to 2.23)), $p=0.029$. $50-69$ years: pre-PP $12.5 \%$, PP year $18.5 \%(\mathrm{OR}=0.65$ (0.47 to 0.91$)), p=0.013$.
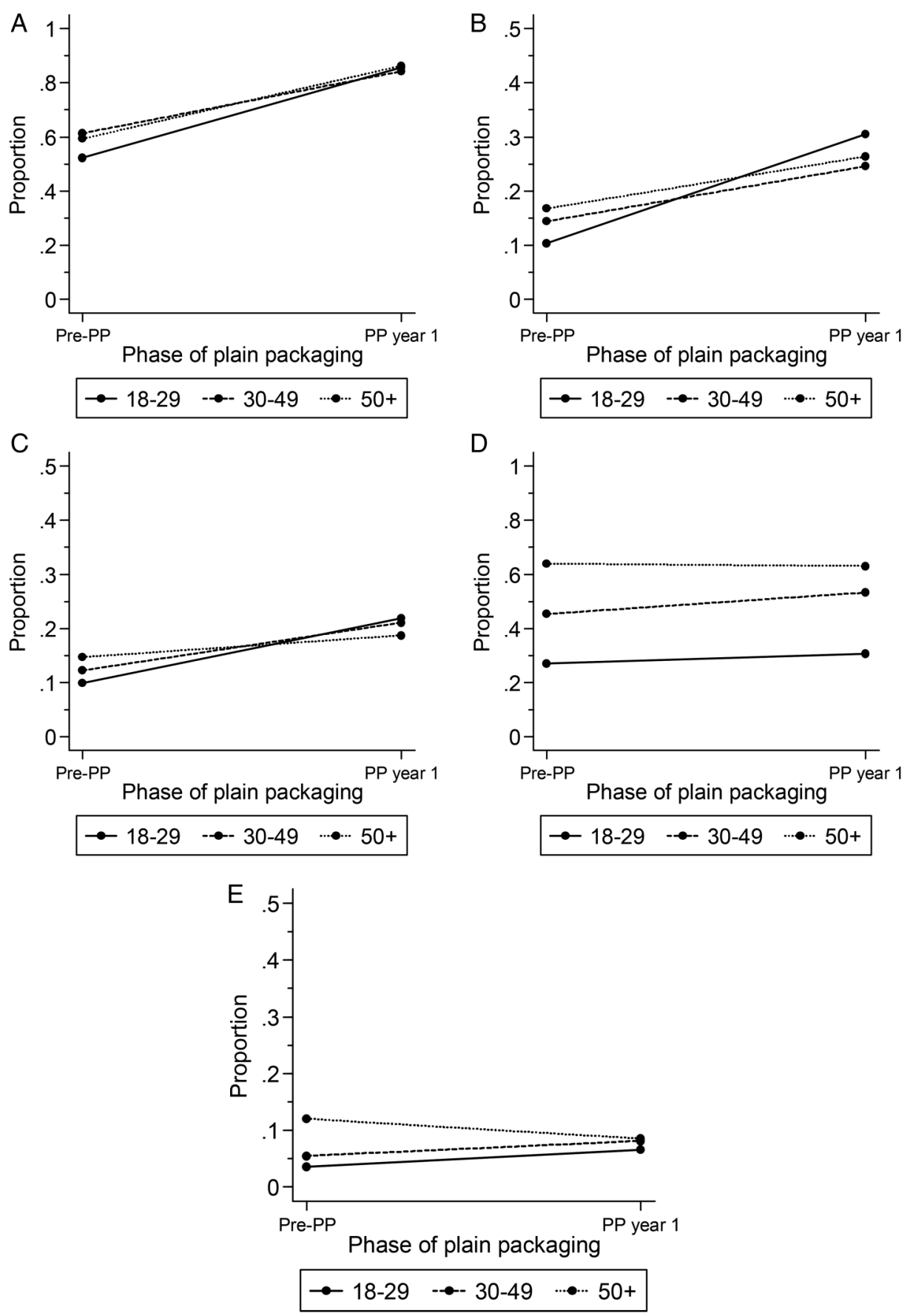

noticeability was maintained throughout PP year 1. Overall, there was no change by phase in perceived exaggeration of the dangers of smoking, although a significant quadratic trend and an examination of the month-by-month data (not presented) pointed to a slight increase in the middle of PP year 1 in the proportion of smokers believing health effects were not exaggerated, followed by a return to its initial level, coinciding with the roll-out of the second set of new GHWs from August 2013. ${ }^{2}$

Compared with pre-PP a greater proportion of smokers in PP year 1 attributed the GHWs with providing much more motivation to quit. The significant linear decline within PP year 1 reflected an early sharp peak followed by a gradual decline to slightly above the baseline level by the end of PP year 1. Avoidant responses increased from pre-PP to PP year
1. There was a sustained increase from pre-PP to PP year 1 in the proportion of smokers who reported concealing their packs or using a different container for their cigarettes, and an immediate and sustained increase in the proportion who had requested a different GHW when purchasing a pack in the past month (table 3). No interactions were found between phase and age, sex or SES for any of the health warning effectiveness outcomes.

\section{Perceived harm outcomes}

Table 4 shows there was a significant increase in the adjusted proportion of smokers who believed that brands do not differ in harmfulness in PP year $1(69.8 \%)$ compared with pre-PP $(65.7 \%)$. There was no change in the belief that one's cigarettes were higher in harmfulness compared with a year ago and 
Table 3 Unadjusted and adjusted percentages, ORs and 95\% Cls from logistic regression models predicting health warning effectiveness outcomes*

\begin{tabular}{|c|c|c|c|c|c|c|c|c|c|}
\hline \multirow[b]{2}{*}{ Variable } & \multicolumn{3}{|c|}{ Comparing phases-unadjusted models } & \multicolumn{3}{|c|}{ Comparing phases—adjusted modelst } & \multicolumn{3}{|c|}{$\begin{array}{l}\text { PP year } 1 \text { trend-adjusted } \\
\text { models }\end{array}$} \\
\hline & Per cent & OR $(95 \% \mathrm{Cl})$ & p Value & Per cent & OR $(95 \% \mathrm{Cl})$ & p Value & Form & OR & $\mathrm{p}$ Value \\
\hline \multicolumn{10}{|c|}{ Notices GHW first when looking at pack $\ddagger(n=7007)$} \\
\hline Pre-PP & 34.4 & 1.00 & & 34.0 & 1.00 & & & & \\
\hline Transition & 44.9 & 1.55 (1.29 to 1.88$)$ & $<0.001$ & 44.9 & $1.60(1.32$ to 1.95$)$ & $<0.001$ & & & \\
\hline PP year 1 & 67.5 & 3.96 (3.51 to 4.48$)$ & $<0.001$ & 67.7 & 4.26 (3.74 to 4.85$)$ & $<0.001$ & Linear & 1.00 & 0.844 \\
\hline \multicolumn{10}{|c|}{ Does not believe dangers of smoking are exaggerated $(n=7163)$} \\
\hline Pre-PP & 65.6 & 1.00 & & 65.1 & 1.00 & & & & \\
\hline Transition & 65.7 & $1.00(0.83$ to 1.22$)$ & 0.969 & 65.7 & $1.03(0.84$ to 1.25$)$ & 0.788 & & & \\
\hline \multirow[t]{2}{*}{ PP year 1} & 63.8 & $0.92(0.82$ to 1.04$)$ & 0.194 & 64.0 & 0.96 (0.84 to 1.08$)$ & 0.470 & Linear & 1.25 & 0.028 \\
\hline & & & & & & & Quad & 0.99 & 0.021 \\
\hline \multicolumn{10}{|c|}{ Attributes much more motivation to quit to GHWs $\ddagger(n=7123)$} \\
\hline Pre-PP & 9.4 & 1.00 & & 9.3 & 1.00 & & & & \\
\hline Transition & 11.8 & 1.28 (0.96 to 1.72$)$ & 0.097 & 11.6 & 1.29 (0.95 to 1.75$)$ & 0.101 & & & \\
\hline PP year 1 & 13.3 & 1.47 (1.21 to 1.77$)$ & $<0.001$ & 13.4 & $1.52(1.25$ to 1.86$)$ & $<0.001$ & Linear & 0.96 & 0.013 \\
\hline \multicolumn{10}{|c|}{ Concealed pack in past month $\ddagger(n=7096)$} \\
\hline Pre-PP & 17.3 & 1.00 & & 17.1 & 1.00 & & & & \\
\hline Transition & 19.0 & $1.12(0.89$ to 1.42$)$ & 0.325 & 19.1 & 1.15 (0.90 to 1.46$)$ & 0.252 & & & \\
\hline PP year 1 & 23.1 & 1.44 (1.24 to 1.66$)$ & $<0.001$ & 23.1 & $1.47(1.26$ to 1.71$)$ & $<0.001$ & Linear & 0.99 & 0.533 \\
\hline \multicolumn{10}{|c|}{ Requested different GHW in past month $\neq(n=7126)$} \\
\hline Pre-PP & 3.9 & 1.00 & & 3.9 & 1.00 & & & & \\
\hline Transition & 8.2 & 2.19 (1.47 to 3.28$)$ & $<0.001$ & 8.5 & $2.28(1.52$ to 3.44$)$ & $<0.001$ & & & \\
\hline PP year 1 & 9.2 & 2.48 (1.90 to 3.24$)$ & $<0.001$ & 9.1 & $2.49(1.89$ to 3.29$)$ & $<0.001$ & Linear & 0.99 & 0.756 \\
\hline
\end{tabular}

no change in the proportions who believed variants do not differ in strength. No significant interactions between phase and age, sex or SES were found for any perceived harm outcome.

\section{Sensitivity testing}

Inclusion of two season variables (last 2 weeks of December; first 2 weeks of January) did not change the pattern of results (see online supplementary appendix A).

Table 4 Unadjusted and adjusted percentages, ORs and 95\% Cls from logistic regression models predicting perceived harm outcomes*

\begin{tabular}{|c|c|c|c|c|c|c|c|c|c|}
\hline & \multicolumn{3}{|c|}{ Comparing phases-unadjusted models } & \multicolumn{3}{|c|}{ Comparing phases-adjusted modelst } & \multicolumn{3}{|c|}{$\begin{array}{l}\text { PP year } 1 \text { trend-adjusted } \\
\text { models }\end{array}$} \\
\hline & Per cent & OR $(95 \% \mathrm{Cl})$ & p Value & Per cent & OR $(95 \% \mathrm{Cl})$ & p Value & Form & OR & p Value \\
\hline \multicolumn{10}{|c|}{ Believes brands do not differ in harmfulness $\ddagger(n=6924)$} \\
\hline Pre-PP & 65.8 & 1.00 & & 65.7 & 1.00 & & & & \\
\hline Transition & 67.0 & $1.06(0.86$ to 1.29$)$ & 0.598 & 67.6 & $1.09(0.89$ to 1.35$)$ & 0.405 & & & \\
\hline PP year 1 & 69.8 & 1.20 (1.06 to 1.36$)$ & 0.004 & 69.8 & 1.21 (1.06 to 1.38$)$ & 0.004 & Linear & 0.97 & 0.012 \\
\hline \multicolumn{10}{|c|}{ Higher harmfulness than a year ago $\S(n=6838)$} \\
\hline Pre-PP & 24.2 & 1.00 & & 23.8 & 1.00 & & & & \\
\hline Transition & 22.1 & 0.89 (0.70 to 1.12$)$ & 0.323 & 21.8 & $0.89(0.70$ to 1.13$)$ & 0.349 & & & \\
\hline PP year 1 & 23.4 & $0.96(0.83$ to 1.10$)$ & 0.532 & 23.6 & $0.99(0.86$ to 1.14$)$ & 0.877 & Linear & 1.00 & 0.811 \\
\hline \multicolumn{10}{|c|}{ Believes variants do not differ in strength $\neq(n=6894)$} \\
\hline Pre-PP & 5.2 & 1.00 & & 5.3 & 1.00 & & & & \\
\hline Transition & 5.9 & $1.16(0.78$ to 1.72$)$ & 0.477 & 5.8 & $1.09(0.72$ to 1.64$)$ & 0.683 & & & \\
\hline PP year 1 & 6.1 & 1.19 (0.92 to 1.55$)$ & 0.178 & 6.1 & $1.15(0.88$ to 1.51$)$ & 0.303 & Linear & 1.01 & 0.812 \\
\hline \multicolumn{10}{|c|}{ *Valid n's for each model vary because of differences in the number of respondents who were eligible for each question (see below) and the number of missing cases for each outcome. } \\
\hline
\end{tabular}




\section{DISCUSSION}

This national study examined the extent to which all three specific objectives of the plain packaging legislation-to reduce appeal of tobacco, increase effectiveness of health warnings and reduce ability of packaging to mislead consumers about smoking harms-were met among adult smokers in the first year after full implementation of the packaging changes.

Compared with a 6-month baseline period, the study found the new packs to be associated with rapid and substantial changes in the direction of reduced appeal which were sustained throughout the first year of full implementation. Of the four appeal variables that required smokers to compare the experience of their current cigarettes with those smoked the year beforehand, the observed increase in effect in the PP year 1 period weakened towards the end of this phase for one variable only (lower pack appeal). As this period late in 2013 required smokers to compare to late 2012 when plain packs were already common, ${ }^{2}$ this regression may reflect a reduction in the specificity of comparison between plain and branded packs, rather than a diminution of the impact of plain packaging per se.

The emergence of lower perceived quality and satisfaction and the increase in beliefs that brands do not differ in prestige among smokers overall (and do not differ in taste for the young-aged and mid-aged population) occurred despite efforts from tobacco companies to reassure consumers that tobacco products would 'remain the same' with the changed packaging. ${ }^{52}$ These findings signifying reduced appeal are consistent with and reinforce the results of past experimental research, ${ }^{10} 11182453$ government-funded pretesting studies to design the Australian packs, ${ }^{7}$ an early study of how smokers responded to the new packaging at the time they emerged onto the market ${ }^{8}$ and a recently published study from one Australian state reporting increases in negative pack perceptions up to 6 months after plain packaging implementation. ${ }^{49}$

It was notable that for three appeal-related variables (pack disliking, quality, satisfaction), young adults evidenced more change than others. Young-aged and middle-aged adults also showed more movement towards believing brands did not differ in taste, and middle-aged smokers showed more movement in believing brands did not differ in prestige than older smokers. This overall pattern of age-related effects for the appeal outcomes was not observed for the health warning or harm perception outcomes. Such specificity of change for the young adult population concurs with the experimental studies of plain packaging which found stronger effects on appeal-related outcomes for younger than older respondents, ${ }^{10}{ }^{11}$ and with the findings of White $e t a l^{32}$ (this supplement) who found reduced pack and brand appeal among adolescents following the introduction of plain packaging in Australia. Furthermore, it is consistent with strong evidence that tobacco branding and image-related factors are very important for young people, ${ }^{12}{ }^{13}$ leading to the conclusion in the 2012 US Surgeon-General's Report that "advertising and promotional activities by the tobacco companies cause the onset and continuation of smoking among adolescents and young adults."13

Our study also found consistent improvements in health warning effectiveness outcomes, including more noticing of warnings, motivation to quit attributed to the warnings, and avoidant behavioural responses. These findings extend those of Dunlop et $a l^{49}$ who found increased noticing of warnings and attribution of encouragement to quit to warnings up to 6 months after implementation of plain packaging with larger GHWs in one Australian state, by demonstrating that such responses were sustained nationally up to 1 year after implementation. While Dunlop et al found increased emotional responses to warnings 6 months after implementation in terms of worry about smoking and wanting to hide or cover packs from the view of others, our study additionally found increased prevalence of reported behavioural actions taken to attempt to avoid warnings (covering up the pack at least several times in the past month; asking for a pack with a different warning) up to 1 year after implementation. Those outcomes are important, since cohort studies suggest that warning avoidance predicts subsequent quitting attempts, ${ }^{40} 4254$ most likely via the association of warning avoidance with increased thinking about smoking harms, ${ }^{54}$ which in turn predicts quit intentions and quit attempts. Avoidant behaviours such as pack concealment can have benefits beyond smokers themselves by reducing exposure of others to tobacco promotion. ${ }^{55}$ Relatedly, an observational Australian study of patrons of outdoor cafes and bars up to a year after plain packaging found a sustained reduction in the visibility of tobacco packs, mostly attributable to fewer packs being left out on display, especially in venues where children were present ${ }^{565}$ (this supplement).

In relation to the third objective of plain packaging, there was increased appreciation after plain packaging that brands do not differ in harm. However, there was no change over time in the perceived harm of one's tobacco compared with a year ago, and no change over time in smokers' beliefs about variants being different in strength. Concepts of 'taste' (measured in the appeal outcomes), 'strength' and 'harm' are strongly related in the minds of smokers. ${ }^{43}$ 58-60 Objectively speaking, cigarette brands and variants do not differ in harmfulness, ${ }^{61} 62$ although an extensive body of research shows many smokers believe they do. ${ }^{1027432963}$ While plain packaging removed the pack colour associated with different brands and variants and replaced it with a consistent drab brown, it placed no limitations on the naming of brands and continued to permit the use of brand variant names including colour names. An observational study of tobacco product developments coinciding with implementation of plain packaging reported incorporation of colour names into longer variant descriptors (eg, 'Dunhill Distinct' became 'Dunhill Distinct Blue') and more expressive brand variant names to evoke the sensation or feature previously connoted only by colour (eg, 'Pall Mall Blue' became 'Pall Mall Rich Blue'). ${ }^{52}$ These developments are clearly designed to reinforce variant differences. Beliefs about strength differences may persist due to the differing perceptions of strength resulting from the sensory experience created by diluted inhaled smoke (from filter ventilation) and strength expectations generated by variant names. $^{212964}$

Study strengths included its national focus and a large sample size, sufficient to compare responses overall and by major demographic subgroups. The continuous tracking survey design enabled comparison of smokers' responses during a preimplementation period, as the new packs transitioned onto the market, and over the first year of full implementation. Observed changes in outcomes were independent of exposure to antismoking mass media campaigns and change in cigarette costliness, and insensitive to seasonal adjustment for the December/January period. As the sample was limited to November 2013, the study further excluded impacts following the 12.5\% December 2013 tobacco tax increase.

A potential study limitation was that since the survey started in April 2012, we did not have responses from one or more years prior to plain packaging implementation to control for the possibility of seasonal effects other than the December-January holiday period. However, it seems unlikely these particular beliefs and behaviours would have been sensitive to season per se. It does however seem likely that the variable presence of educational interventions would affect such beliefs, and for this 
reason we adjusted for antismoking media campaign activity. We further note the findings of Dunlop $e t a l^{49}$ who found similar increases for a subset of variables similar to ours up to 6 months into plain packaging compared with 1-6 years pre-PP using time series analyses which adjusted for seasonality.

On the basis of the findings of this study, we conclude that the first two objectives of the legislation relating to reducing appeal and increasing GHW effectiveness have been achieved among adult smokers. This study suggests that the third objective of reducing the extent to which smokers are misled about the harms of smoking has been partially met. Perceptions of differential harmfulness may be maintained by the naming of brand variants which are still permitted to emphasise colour and other product characteristics, suggesting future standardised packaging laws should further limit such variant names.

\section{What this paper adds}

- Compared with a pre-plain packaging period, the first year of Australian implementation of plain packaging with larger graphic health warnings saw reduced appeal and increased health warning effectiveness, and some improvement in correcting misperceptions of harms in a national sample of adult cigarette smokers.

- There was greater change for four appeal-related outcomes for young (18-29 years) adults and two appeal-related outcomes for mid-aged (30-49 years) adults, with no differences by age, sex or socioeconomic status for other outcomes.

- The specific objectives of plain packaging have been achieved among adult smokers and were generally sustained up to 12 months after implementation.

Acknowledgements The authors thank Professor Ron Borland for sharing questions from the ITC-survey for inclusion in the telephone tracking survey, the Social Research Centre for data collection and Megan Bayly for data checking.

Contributors MW and MS designed the study. KC and MZ cleaned data files, undertook analysis and reported results. SD and EB provided additional advice on analysis and interpretation of results. MW drafted the manuscript with contributions from all authors. All authors approved the final manuscript.

Funding The National Plain Packaging Tracking survey was funded under a contract with the Australian Government Department of Health and Ageing.

Competing interests The authors wish to advise that MW was a member and MS a technical writer for the Tobacco Working Group of the Australian National Preventive Health Task Force and MW was a member of the Expert Advisory Committee on Plain Packaging that advised the Australian Department of Health on research pertaining to the plain packaging legislation. MW, SD and EB hold competitive grant funding from the Australian National Health and Medical Research Council and MW holds competitive grant funding from the US National Institutes of Health, Australian National Preventive Health Agency and BUPA Health Foundation.

Ethics approval The survey was approved by the Cancer Council Victoria Human Ethics Committee (HREC 0018).

Provenance and peer review Not commissioned; externally peer reviewed.

Open Access This is an Open Access article distributed in accordance with the Creative Commons Attribution Non Commercial (CC BY-NC 4.0) license, which permits others to distribute, remix, adapt, build upon this work non-commercially, and license their derivative works on different terms, provided the original work is properly cited and the use is non-commercial. See: http://creativecommons.org/ licenses/by-nc/4.0/

\section{REFERENCES}

1 Tobacco Plain Packaging Act 2011. No. 148, 2011 as amended. 2011. http://www. comlaw.gov.au/Details/C2013C00190

2 Scollo M, Lindorff K, Coomber K, et al. Standardised packaging and new enlarged graphic health warnings for tobacco products in Australia-legislative requirements and implementation of the Tobacco Plain Packaging Act 2011 and the Competition and Consumer (Tobacco) Information Standard 2011. Tob Control 2015;24:ii9-16.

3 Competition and Consumer (Tobacco) Information Standard. 2011. http://www. comlaw.gov.au/Details/F2013C00598

4 Gfk Blue Moon. Market testing of new health warnings and information messages for tobacco product packaging: phase 1 side of pack messages. Canberra: Department of Health and Ageing, 2011. http://www.health.gov.au/internet/main/ publishing.nsf/Content/mr-plainpack

5 Gfk Blue Moon. Market testing of new health warnings and information messages for tobacco product packaging: phase 2 front and back of pack messages. Canberra: Department of Health and Ageing, 2011. http://www.health.gov.au/ internet/main/publishing.nsf/Content/mr-plainpack

6 Gfk Blue Moon. Market testing of new health warnings and information messages for tobacco product packaging: phase 3 refinement of health messages. Canberra: Department of Health and Ageing, 2011. http://www.health.gov.au/internet/main/ publishing.nsf/Content/mr-plainpack

7 Gfk Blue Moon. Market research reports on tobacco plain packaging of tobacco products. Canberra: Department of Health and Ageing, 2011. http://www.health. gov.au/internet/main/publishing.nsf/Content/mr-plainpack

8 Wakefield MA, Hayes L, Durkin S, et al. Introduction effects of the Australian plain packaging policy on adult smokers: a cross-sectional study. BMJ Open 2013;3:7.

9 Quit, Cancer Council Victoria. Plain packaging of tobacco products: a review of the evidence. Melbourne, Australia: Cancer Council Victoria, May (updated August 2011) 2011. http://www.cancer.org.au/content/pdf/CancerControlPolicy/ PositionStatements/TCUCCVBkgrndResrchPlainPak270511ReEnd_FINAL_May27.pdf

10 Stead M, Moodie C, Angus K, et al. Is consumer response to plain/standardised tobacco packaging consistent with framework convention on tobacco control guidelines? A systematic review of quantitative studies. PLOS ONE 2013:8:e75919.

11 Hammond D. Standardized packaging of tobacco products: evidence review. Prepared on behalf of the Irish Department of Health. Waterloo, Ontario, Canada: University of Waterloo, March 2014. http://www.tri.ie/news/2014/ new-irish-focused-review-on-plain-packaging.aspx

12 National Cancer Institute. The role of the media in promoting and reducing tobacco use. Tobacco Control Monograph No 19. Bethesda, MD: US Department of Health and Human Services, National Institutes of Health, National Cancer Institute, June 2008. NIH Pub No 07-6242. http://cancercontrol.cancer.gov/tcrb/monographs/19/ index.html

13 US Department of Health and Human Services. Preventing Tobacco use among youth and young adults: a report of the surgeon general. Report. Atlanta, Georgia: U.S. Department of Health and Human Services, Public Health Service, Office of the Surgeon General, Rockville, MD, 2012. http://www.cdc.gov/tobacco/data_statistics/ sgr/2012/index.htm

14 United States v. Philip Morris USA. 449 F. Supp. 2d 1, (D.D.C., 2006) 980.

15 Scollo M, Bayly M, Wakefield M. Plain packaging - a logical progression for tobacco control in one of the world's 'darkest markets'. Tob Control.

16 Moodie CS, Mackintosh AM. Young adult women smokers' response to using plain cigarette packaging: a naturalistic approach. BMJ Open 2013;3:e002402.

17 Moodie C, Bauld L, Ford A, et al. Young women smokers' response to using plain cigarette packaging: qualitative findings from a naturalistic study. BMC Public Health 2014;14:812

18 Gallopel-Morvan K, Moodie C, Eker F, et al. Perceptions of plain packaging among young adult roll-your-own smoker in France: a naturalistic approach. Tob Control Published Online First: 11 Jun 2014 doi:10.1136/tobaccocontrol-2013-051513

19 Wakefield M, Germain D, Durkin S. How does increasingly plainer cigarette packaging influence adult smokers' perceptions about brand image? An experimental study. Tob Control 2008;17:416-21.

20 Hammond D, Doxey J, Daniel S, et al. Impact of female-oriented cigarette packaging in the United States. Nicotine Tob Res 2011;13:579-88.

21 Doxey J, Hammond D. Deadly in pink: the impact of cigarette packaging among young women. Tob Control 2011;20:353-60.

22 Moodie C, Mackintosh AM, Hastings $G$, et al. Young adult smokers' perceptions of plain packaging: a pilot naturalistic study. Tob Control 2011;20:367-73.

23 Gallopel-Morvan K, Moodie C, Hammond D, et al. Consumer perceptions of cigarette pack design in France: a comparison of regular, limited edition and plain packaging. Tob Control 2012;21:502-6.

24 Guillaumier A, Bonevski B, Paul C, et al. Socioeconomically disadvantaged smokers' ratings of plain and branded cigarette packaging: an experimental study. BMJ Open 2014:4:e004078.

25 Germain D, Wakefield M, Durkin S. Adolescents' perceptions of cigarette brand image: does plain packaging make a difference? J Adolesc Health 2010;46:385-92.

26 Bansal-Travers M, Hammond D, Smith P, et al. The impact of cigarette pack design, descriptors, and warning labels on risk perception in the U.S. Am J Prev Med 2011:40:674-82

27 Hammond D, Dockrell M, Arnott D, et al. Cigarette pack design and perceptions of risk among UK adults and youth. Eur J Public Health 2009;19:631-7.

28 White CM, Hammond D, Thrasher JF, et al. The potential impact of plain packaging of cigarette products among Brazilian young women: an experimental study. BMC Public Health 2012;12:737. 
29 Hammond D, Daniel S, White CM. The effect of cigarette branding and plain packaging on female youth in the United Kingdom. J Adolesc Health 2013;52:151-7.

30 Goldberg M, Liefeld J, Madil J, et al. The effect of plain packaging on response to health warnings. Am J Public Health 1999;89:1434-5.

31 Beede P, Lawson R. The effect of plain packages on the perception of cigarette health warnings. Public Health 1992;106:315-22.

32 White V, Williams T, Wakefield M. Has the introduction of plain packaging with larger graphic health warnings changed adolescents' perceptions of cigarette packs and brands? Tob Control 2015;24:ii42-9.

33 White V, Williams T, Faulkner A, et al. Do larger graphic health warnings on standardised cigarette packs increase adolescents' cognitive processing of consumer health information and beliefs about smoking related harms? Tob Control 2015;24:ii50-7.

34 IARC Handbooks of Cancer Prevention. Tobacco control, Volume 12: Methods for evaluating tobacco control policies. Lyon, France: International Agency for Research on Cancer, 2008

35 Brennan E, Durkin S, Coomber K, et al. Are quitting-related cognitions and behaviours predicted by proximal responses to plain packaging with larger health warnings? Findings from a national cohort study with Australian adult smokers. Tob Control 2015;24:ii33-41.

36 Durkin S, Brennan E, Coomber $\mathrm{K}$, et al. Short-term changes in quitting-related cognitions and behaviours after the implementation of plain packaging with larger health warnings: findings from a national cohort study with Australian adult smokers. Tob Control 2015;24:ii26-32.

37 Lavrakas PJ. Within-household respondent selection: how best to reduce total survey error? Media Rating Council Inc., November. 2008. http://www.mediaratingcouncil. org/MRC\%20Point\%20of\%2OView\%20-\%20Within\%20HH\%2ORespondent\% 20Selection\%20Methods.pdf

38 Coomber K, Zacher M, Durkin S, et al. Australian National Tobacco Plain Packaging Tracking Survey: Technical Report. Melbourne: Cancer Council Victoria and Social Research Centre, December 2014. http://tobaccocontrol.bmj.com/lookup/suppl/ doi:10.1136/tobaccocontrol-2014-052050/-IDC1

39 Shanahan P, Elliott D. Evaluation of the effectiveness of the graphic health warnings on tobacco product packaging 2008. Canberra, Australia: Australian Government Department of Health and Ageing, 2009. http://www.health.gov.au/internet/main/ publishing.nsf/Content/tobacco-warn-eval08

40 Borland $\mathrm{R}$, Yong $\mathrm{HH}$, Wilson $\mathrm{N}$, et al. How reactions to cigarette packet health warnings influence quitting: findings from the ITC Four-Country survey. Addiction 2009;104:669-75.

41 Hammond D, Fong GT, Borland R, et al. Text and graphic warnings on cigarette packages: findings from the international tobacco control four country study. Am J Prev Med 2007:32:202-9.

42 Hammond D, Fong GT, McDonald PW, et al. Graphic Canadian cigarette warning labels and adverse outcomes: evidence from Canadian smokers. Am J Public Health 2004;94:1442-5.

43 Hammond D, Parkinson C. The impact of cigarette package design on perceptions of risk. J Public Health (Oxf) 2009;31:345-53.

44 Heatherton TF, Kozlowski LT, Frecker RC, et al. Measuring the heaviness of smoking: using self-reported time to the first cigarette of the day and number of cigarettes smoked per day. Br J Addict 1989;84:791-9.

45 Australian Bureau of Statistics. Technical paper: socio-economic indexes for areas (SEIFA) 2011. Canberra, Australia: Australian Bureau of Statistics, 2013. Catalogue no. 2033.0.55.001. http://www.abs.gov.au/ausstats/abs@.nsf/mf/2033.0.55.001/

46 Wakefield M, Spittal M, Durkin S, et al. Effects of mass media campaign exposure intensity and durability on quit attempts in a population-based cohort study. Health Educ Res 2011;26:988-97.
47 Dunlop S, Cotter T, Perez D, et al. Televised antismoking advertising: effects of level and duration of exposure. Am J Public Health 2013;103:e66-73.

48 Australian Bureau of Statistics. Average weekly earnings, Australia. Cat No 6302.0. November 2013. http://www.abs.gov.au/ausstats/abs@.nsf/mf/6302.0

49 Dunlop SM, Dobbins T, Young JM, et al. Impact of Australia's introduction of tobacco plain packs on adult smokers' pack-related perceptions and responses: results from a continuous tracking survey. BMJ Open 2014;4:e005836.

50 StataCorp. Stata Statistical Software: release 12. College Station, TX: StataCorp LP, 2011.

51 Durkin S, Wakefield M, Spittal M. Which types of televised anti-tobacco campaigns prompt more quitline calls from disadvantaged groups? Health Educ Res 2011;26:998-1009.

52 Scollo M, Occleston J, Bayly M, et al. Tobacco product developments coinciding with the implementation of plain packaging in Australia. Tob Control Published Online First: 30 Apr 2014 doi:10.1136/tobaccocontrol-2013-051509

53 Brose $L S$, Chong CB, Aspinall E, et al. Effects of standardised cigarette packaging on craving, motivation to stop and perceptions of cigarettes and packs. Psychol Health 2014;29:849-60.

54 Yong $\mathrm{HH}$, Borland R, Thrasher JF, et al. Mediational pathways of the impact of cigarette warning labels on quit attempts. Health Psychol 2014;33:1410-20.

55 Ferraro R, Bettman J, Chartrand TL. The power of strangers: the effect of incidental consumer brand encounters on brand choice. J Consum Res 2009;35:729-41

56 Zacher M, Bayly M, Brennan E, et al. Personal tobacco pack display before and after the introduction of plain packaging with larger pictorial health warnings in Australia: an observational study of outdoor café strips. Addiction 2014;109: 653-62.

57 Zacher M, Bayly M, Brennan E, et al. Personal pack display and active smoking at outdoor café strips: assessing the impact of plain packaging 1 year postimplementation. Tob Control 2015;24:ii94-7.

58 Mutti S, Hammond D, Borland R, et al. Beyond light and mild: cigarette brand descriptors and perceptions of risk in the International Tobacco Control (ITC) Four Country Survey. Addiction 2011;106:1166-75.

59 Brown A, McNeill A, Mons U, et al. Do smokers in Europe think all cigarettes are equally harmful? Eur J Public Health 2012;22:35-40.

60 Elton-Marshall T, Fong GT, Yong HH, et al. Smokers' sensory beliefs mediate the relation between smoking a 'light/low tar' cigarette and perceptions of harm. Tob Control Published Online First: 4 Nov 2014 doi:10.1136/tobaccocontrol-2014051977

61 National Cancer Institute Expert Committee. NCI monograph no. 8: changes in cigarette-related disease risks and their implication for prevention and control. Bethesda, MD: National Institutes of Health, 1997. http://onlinebooks.library.upenn. edu/webbin/book/lookupid?key=olbp24454

62 National Cancer Institute. Risks associated with smoking cigarettes with low machine-measured yield of tar and nicotine. Bethseda, MD: US Department of Health and Human Services National Institutes of Health, National Cancer Institute, October 2001. NIH Pub. No 02-5074. http://cancercontrol.cancer.gov/TCRB/ monographs $/ 13 / \mathrm{m} 13$ preface.pdf

63 O'Connor RJ, Caruso RV, Borland R, et al. Relationship of cigarette-related perceptions to cigarette design features: findings from the 2009 ITC U.S. Survey, Nicotine Tob Res 2013;15:1943-7.

64 Wakefield M, Morley C, Horan J, et al. The cigarette pack as image: new evidence from tobacco industry documents. Tob Control 2002;11:i73-80. 